\title{
De mãos vazias perante a morte: Sobre o vazio de Deus em Vergílio Ferreira
}

\section{Empty-handed before death: On the emptiness of God in Vergílio Ferreira}

\section{*Pedro Pereira}

Texto enviado em

26.01.2021

Aprovado em

22.03.2021

V. 11 - N. 23 - 2021

*Universidade Católica Portuguesa- UCP. Contato: pedro.pereira@lusofrances.com.pt 
como um ser em processo e, portanto, que sobrevive [ilusoriamente?] à catástrofe da transitoriedade. Vergílio impõe a reflexão sobre o que permanece do sujeito em processo de ser, um sujeito que efetivamente só se descobre na memória, interpretada como espaço de recriação e de significação. Mais do que indagar sobre as possibilidades do divino, a obra de Vergílio Ferreira pode ser interpretada como a procura de uma afirmação do eterno, como conjunto de instruções sobre como morrer, que permita ver a morte como síntese e harmonia de tudo o que se concebe no reino profícuo das possibilidades [Estrela Polar]. No fundo, a fim de realçar o legado do ser, mostra-se o Homem na diáspora por Deus, o que o expõe na sua ambivalência como ser de fronteira: entre o eterno [da memória, da capacidade, do sonho] e o futuro [que esconde sempre a morte, o vazio e a solidão].

Palavras-chave: Filosofia; Literatura; Deus; Morte; Vergílio Ferreira.

\section{Abstract}

The philosophical density of Vergílio Ferreira's work is established at the frontiers of the game between finitude and the transcendent. From Aparição to Estrela Polar, through Em Nome da Terra or Para Sempre, the drama of existence breaks with the apparent meaning of the subject's meaning, opening it up to ontological drift and the rescue of past time as conditions for existential understanding. In the suffering of those who remember, we see the remorse of incompleteness, frugality and ephemerality, which lead the subject to a paradoxical search for the divine [either as a metaphysical entity or as a creative potential of a being confined to the limitations and potential of a body]. God is, simultaneously, the condition for the affirmation of the subject's creative freedom and the agonizing verification of the absurdity of existing. God appears, then, in the work of Vergílio Ferreira, as a pendulum between the will to affirm and the absurdity of the possibilities. From the ambivalence of God's place, Man emerges as being launched into existence and absorbed in guilt. Man as a potential for creation that is capable of the most exacerbated capacity to look at Time, to remember. The Man who sees himself as a being in process and, therefore, who survives [illusory?] The catastrophe of transience. Vergílio imposes a reflection on what remains of the subject in the process of being, a subject that is effectively only discovered in memory, interpreted as a space for recreation and meaning. More than inquiring about the possibilities of the divine, the work of Vergílio Ferreira can be interpreted as the search for an affirmation of the eternal, as a set of instructions on how to die, which allows one to see death as a synthesis and harmony of everything conceived in the fruitful realm of possibilities [Estrela Polar]. Basically, in order to highlight the legacy of being, Man is shown in the diaspora by God, which exposes him in his ambivalence as a frontier being: between the eternal [of memory, capacity, dream] and the future [that always hides death, emptiness and loneliness].

Keywords: Philosophy, Literature; God; Death; Vergílio Ferreira 
om uma vida que atravessa a quase totalidade do século $X X$, a estreia literária de Vergílio Ferreira ocorre em 1943 com a publicação de O Caminho Fica Longe, numa época de convulsão social, de inovação tecnocientífica e, sobretudo, de catástrofe dos humanismos e das afirmações do poder humano ${ }^{1}$. Cinco anos antes, Sartre publicava, ainda antes de conhecer o cativeiro nazi, $A$ Náusea, obra que expunha a degradação da axiologia moderna e que exigia a centralidade da reflexão do homem sobre a sua situação concreta. Um enquadramento circunstancial difuso que permite compreender que, nas suas múltiplas valências, a obra literária de Vergílio Ferreira se estabeleça na fratura da imanência e do transcendente, apresentando o homem no jogo agónico do existir enquanto ser fragmentado entre as possibilidades criativas e a angústia da efemeridade². De Aparição a Estrela Polar, passando por Em Nome da Terra ou Para Sempre, assistimos ao drama da existência no romper do sentido aparente da significação do sujeito, abrindo-o à deriva ontológica e ao resgate do tempo como condições para a compreensão existencial. É nesta intersecção do ser e do não-ser que o confronto do homem com a evidência da efemeridade abre à interrogação filosófica pelo sentido e introduz a deriva pelo divino.

Em Em Nome da Terra, Vergílio estabelece o programa de uma parte significativa da sua obra: escreve para aprender a morrer, para aceitar legar ao Tempo o que eterniza o Homem. Evocando o passado, procura

1. Em Um Escritor Apresenta-se, Vergílio realça que nasceu "para a literatura nos fins da II Guerra Mundial. A esperança ou a certeza, quebradas depois na dúvida e na questionação alargada, foi a sorte que [Ihe] coube". Cf. Vergílio Ferreira, Um Escritor Apresentase, INCM, Lisboa, 1981, p. 199.

2. Em Invocação ao Meu Corpo, obra ensaística de 1969, Vergílio alerta para a solidão do homem contemporâneo. O otimismo [e a desmesura] da técnica, catalisadora das transformações sociais dos séculos XIX e XX, culminam no isolamento do homem que "ficou a sós com o universo para um diálogo a sós com ele" [213]. A reclamação da liberdade do sujeito, conducente à disrupção dos códigos éticos e morais do passado, que encontra expressão na afirmação nietzschiana da superação de Deus pelo Homem, permite um horizonte de inteligibilidade do cataclismo e da catástrofe do século XX. $\mathrm{O}$ homem vergiliano está estreitamente imbuído das conotações ontológicas provocadas pela transmutação conceptual decorrentes desta afirmação da técnica sobre o homem. 
recriar o sentido, resgatando ao silêncio e ao vazio o que a mudança reclamara para si. Arredado da convivencialidade e da socialidade, a história de João desenvolve-se entre a efervescência da memória e a apostasia do futuro, confrontando-se com a premência do resgate ao oblívio de uma significação que tolere a finitude. Pela rememoração, confronta-se a denotação dionisíaca [determinada de forma nietzschiana] do ser humano, aberto ao tempo enquanto entidade potencial, como ser a fazer, com a consciência do sujeito determinado como habitante do espaço fronteiriço do tempo em que "a gente se aposenta de ser gente ${ }^{3 ", ~ e m ~}$ que resta "viver do espírito" por "já não se ter corpo para acompanhar". Assim, estabelecem-se os trâmites do jogo transimanente que conota a diáspora existencial de um ser que se faz na relação com um corpo, simultânea e ambivalentemente condição de potencialidade e sinonímico de definhamento e corrupção. Se pelo corpo ${ }^{5}$ se acede à circunstancialidade da existência, é pela memória, na auscultação do passado, que se acede ao essencial do sujeito. Recordar será, então, permitir o tempo que leva a saber ${ }^{6}$, uma vez que o balanço da humanidade se faz somente na eternidade ${ }^{7}$, emergindo a memória como lugar do eterno e acentuando o divino do ser que cria, o apolíneo que contrasta com a incomensurabilidade nilista que se esconde nas promessas de futuro.

A transitoriedade que Em Nome da Terra estabelece entre o transcendente e o imanente, entre o divino e o humano, surge em novos moldes: é a imanência [de um corpo, de uma circunstância, de uma experiência] que suporta a transcendência [que é o sentido do vivido]. O corpo, enquanto espaço de possibilidade e significação, surge, aliás, como fonte de inveja divina, na medida em que inutiliza Deus como res-

3. Vergílio Ferreira, Em Nome da Terra, Quetzal, 2009, p.18.

4. Ibid, p.25.

5. Veja-se que em Em Nome da Terra, as principais personagens se veem desfasadas do seu corpo. João, protagonista, não apenas se vê despedaçado de uma perna, como definha num asilo de idosos em que só lhe resta o espectro da morte; Mónica, esposa de João, perde-se na doença, alienada de si mesma; finalmente, Teodoro renuncia ao corpo na dedicação de si mesmo ao divino, professando votos religiosos.

6. Ibid. p.46.

7. Ibid. p.136. 
guardo da transitoriedade. Contrariamente à proposta dualística cartesiana, Vergílio abre a memória como externalização à condição disfórica do ser humano, permitindo a divinização do Homem. Pela memória, o homem transmuta-se em Deus, sobrevivendo à perda e ao vazio. Mas Em Nome da Terra é uma obra de alcance destrutivo. Desconcerta, incomoda, perturba e, sobretudo, amargura, impondo a frugalidade do ser quando exposto ao Tempo. Enquanto rememora, buscando no passado a compreensibilidade de si mesmo, João, na sua degenerescência, enquanto, no fundo, aguarda a morte, procura deter o Tempo. No seu definhamento, pede o retrato dos filhos enquanto crianças, o que lhe é negado pela própria filha, Márcia, num sinal de transitoriedade que recorda o inútil a que o Tempo vota os sonhos e as vontades. Dirigindose à memória da mulher, Mónica, João confessa que "os filhos são uma invenção da nossa fraqueza para compensar a morte, o modo mais barato de se ser eterno. Um modo proletário de se ser Deus ${ }^{8 "}$, porquanto são expressão da vontade e da pulsão criativa do sujeito. A recusa de Márcia é o contrapeso do que se cria: "prepararmo-nos para a morte é", continua Vergílio pela voz de João, "irmos morrendo tudo até ficarmos só cheios de nós"', aceitando o despojamento do acessório que é aquilo que é externo ao indivíduo.

A morte é ubíqua em Em Nome da Terra, presa no âmago do homem que se descobre no sofrimento imbuído no ir-se perdendo de si. Esta perda decorre explicitamente da demência de Mónica, mas também na perda de futuro de João [esquecido num lar em que espera a morte]. É Mónica quem interroga: "porque é que estás sempre a lembrar o que se passou? ${ }^{10 "}$ A resposta chegaria narrativamente mais tarde, quando João contrapõe o futuro como espaço estéril ("querias que me voltasse para o futuro onde está a morte?"11) e ainda quando estabelece a memória

\footnotetext{
8. Id., Em Nome da Terra, p.40.

9. Ibid, p.41.

10. Ibid, p.46.

11. Ibid, p.132.
} 
como lugar do eterno ${ }^{12}$. Apesar de nela consistirem as potencialidades do sentido e a configuração demiúrgica do homem, a memória não deixa de surgir também na sua insuficiência como possibilidade de (re)construção essencialista, mostrando, mais do que a inteligibilidade do passado, a inutilidade do futuro. João confessa que a noite não custa; o que custa é o anoitecer ${ }^{13}$, o que custa é o saber-se condenado a desaparecer. Paradoxalmente, a consequência destas lições de morte, e o verdadeiro sentido da interrogação primeva que todo o homem comporta em si, está na aceitação da vida enquanto exercício de solidão ${ }^{14}$, evocando-se o passado como ambulatório e como iniciação à morte.

No jogo entre o efémero e o eterno, a morte surge, no IV volume de Espaço do Invisível, como condição matricial para a demarcação da liberdade do sujeito. A angústia existencialista de nos vermos adjacentes à efemeridade e ao definhamento está "fundada na liberdade, nasce da vertigem do Nada"15 enquanto condição para a recuperação do si-mesmo que o sujeito opera [uma vez mais] pela memória. Em Aparição, esta nadificação expõe-se quando Alberto se afasta do espaço primevo em que a comunhão e a felicidade eram possíveis. O abandono da montanha é a atualização da escapatória à treva da caverna platónica, confirmando o homem como referencial do homem. Alberto é, então, o estafeta dos novos deuses, já não celestes, mas imanentes. É o confidente da verdade que pulsa no seu âmago e que mais não é do que a convicção do imenso de cada sujeito. Seja por incapacidade do mensageiro seja pela amplitude da mensagem, a missão de Alberto colide com a esterilidade do meio eborense. A mesma impossibilidade de transmissibilidade da verdade autêntica de cada um ecoa nas páginas de Para Sempre. Aqui, acompa-

12. Cf. Ibid, p.169.

13. Cf. Ibid, p.123.

14. Vergílio Ferreira, em Espaço do Invisível, cita Teillard de Chardin, concordando que "o máximo de individualismo coincidiu com o máximo de solidão", mostrando como a afirmação do valor intrínseco do sujeito colide com a socialidade da mensagem. Aparição, por exemplo, expõe a inutilidade da transmutação dos valores e da afirmação do individualismo, mostrando que nada mais restaria do que o abandono e o silêncio a quem desafia a convenção.

15. Vergílio Ferreira, Espaço do Invisível, Vol. IV, INCM, 1987, p.58. 
nhamos Paulo no esforço agónico de rememoração do sentido perdido. Apesar de abrir e fechar com a expressão "para sempre", a obra conduz à afirmação desconcertante do Nada. Para Sempre é uma obra [quase] niilista, porquanto nada sobra do homem que se fora. Paulo perde a infância e as referências educativas das tias que sobraram ao silêncio da mãe; perde Sandra enquanto recetáculo de certezas; perde Alexandra, a filha que o mundo alienado reclama para si; e perde-se, finalmente, a si, sobretudo nos lamentos das memórias que lhe restaram.

A Paulo resta os fantasmas da autenticidade e a pretensão de se "ser inteiro no exacto instante em que se é". Mas no esforço de ser, percebe-se a perda e na reconstrução posterior do que se fora, sobeja a ausência. No fundo, nunca se é; vai-se sendo... Vergílio reconhece que o Tempo é a nossa modificação ${ }^{16}$, o que impõe a impossibilidade ontológica de um ser que resista, abrindo-nos a um existencialismo pessimista que nos oferece a plena responsabilidade no conciliábulo do Nada. Das vicissitudes, Paulo, por Ihes sobreviver e resistir, é o único culpado. $\mathrm{Na}$ afirmação da liberdade e da potencialidade do sujeito, emerge a responsabilização e, sobretudo, a culpabilização que torna o rememorar [na ilusão de um sentido que, pelo menos, tolere ou reconforte] uma propagação da dor de nada restar. Nem mesmo a dor.

Para Sempre esconde a chave de leitura de uma parte significativa da obra vergiliana. Todo o capítulo XXVII, mas concretamente a página 219, procura apurar "o que [se tem] para enfrentar a morte? O que é que a morte vem matar? ${ }^{17 "}$ Toda a rememoração encontra nesta interrogação o seu nexo. As múltiplas e constantes analepses e prolepses que caracterizam a obra de Vergílio e que acentuam o tormento das personagens procuram determinar o que se tem para dar à morte. Paulo, por exemplo, necessita, depois de uma vida ausente, de retornar à casa fechada da

16. Vergílio Ferreira, Para Sempre, Quetzal, 2008, p.169. No entanto, não deixa de reconhecer a possibilidade da memória abrir para "um tempo de eternidade sem passado nem futuro". Cf. ainda ibid, p.143.

17. Ibid, p. 219. 
infância, vendo neste regresso uma condição para a aprendizagem da morte. A memória, quase como exame de consciência, é uma expressão mais ampla deste retorno telúrico onde se confrontam os fantasmas que deambulam o sentido [ou a sua ausência] do que tempo que fora, numa indagação sobre o que a morte leva de quem vive, animando-se na expectativa de algo que resista. Mas enquanto os violinos do passado ecoam Schubert, Paulo tem as mãos repletas de nada para ressarcir a Morte ${ }^{18}$, confessando que "tudo é sombra e fim e terror e cansaço"19.

Esta redução do sujeito e a sua aparição a si mesmo como ser-para-a-morte estabelece a influência existencialista da obra de Vergílio. Testemunha da desmura do consequencialismo tecnológico que, ampliando as possibilidades de ação humana, esgotam o homem na ausência de sentido ontológico, o século $X X^{20}$ impõe-nos o termo da perceção moderna do sujeito, principalmente enquanto entendido como entidade racionalizadora do mundo, afastando a preocupação epistemológica e centrando a reflexão filosófica no âmago da existência. Sendo Aparição a melhor transposição da falibilidade das capacidades gnosiológicas do sujeito, [porquanto Alberto, movido pela pulsão de compreensibilidade, culmina, como o homem contemporâneo, obliterado pela incapacidade que o confina à angústia ou ao silêncio], também João, em Em Nome da Terra, e Paulo, em Para Sempre, explanam as diferentes conotações existencialistas [seja Kierkegaard e a referencialidade da existência enquanto existência-para-Deus; seja Heidegger com a perceção da finitude como existência-para-a-morte; seja Sartre e a existência-para-o-nada], estabelecendo-se como predicados do homem contemporâneo o desamparo, a queda e a solidão ${ }^{21}$. Mas além deste enquadramento na senda existencialista heideggariana e sartriana, subjaz profundamente a perceção da

18. Cf. Vergílio Ferreira, Para Sempre, Quetzal, 2008 p.219.

19. Cf. Ibid, p.256.

20. Vergílio Ferreira nasce em 1916 e publica a sua primeira obra em 1943. Nascido no enquadramento bélico da I Guerra Mundial, aparece como autor em plena II Guerra Mundial.

21. Cf. Eduardo Lourenço, Obras Completas - Heterodoxias, Fundação Calouste Gulbenkian, 2012, p.243. 
irredutibilidade do sujeito às circunstâncias, viabilizando a aproximação ao existencialismo kierkegaardiano que nos mostra um aspeto central das personagens dos romances de Vergílio: mais que uma consequência contingencial, mais do que um processo do Zeitgeist hegeliano ${ }^{22}$, o homem surge[-se] como definidor da existência, cabendo-lhe a tarefa de determinação e significação. Kierkegaard reserva o estatuto de autonomia para o homem que transcende os trâmites sensualistas e éticos e dedique a sua existência à vivência dos preceitos divinos ${ }^{23}$, mostrando o transcendente como real condição de possibilidade do imanente ${ }^{24}$, concretizando a ausência de Deus como obsolescência existencial ${ }^{25}$, porquanto a separabilidade do horizonte de perfetibilidade que representa Deus remete para a angústia e o desespero das respostas frugais a que ficam votadas as existências sensualistas. No entanto, não deixa de expor como condição estrutural do sujeito a sua autonomia e irredutibilidade contextual. $\mathrm{Na}$ afirmação da sua plena liberdade, radicalmente estabelecida pela circunstancialidade da vida, Kierkegaard apresenta o homem na impossibilidade de uma existência abstraída de si mesmo, apesar de estipular a separabi-

22. O conceito de ideia enquanto síntese holística das circunstancialidade, que lhe conferem densidade e coesão, permitindo estabelecer a pertence do sujeito ao que o transcende e, portanto, absorve.

23. Só dessa forma se superará a intransponibilidade corpórea e as suas determinações ônticas sobre o sujeito. O Tempo, balizando a ação do sujeito, remete-nos para o corpo, para o estético, devendo o sujeito ascender a planos de sentido que, escapando à temporalidade, garantem a autenticidade. Cf. Soren Kikergaard, Temor ou Tremor, Guimarães Editores, 1990.

24. A consequência de uma existência votada aos trâmites do corpo e da sensualidade culminam no desperdício existencial. Saliente-se, a este propósito, a hierarquização existencial decorrente dos múltiplos estados da existência humana: a tendência para o corpo encerra o sujeito numa vivência contingente, particularizada e efémera; a abertura ao outro estabelece-o no âmago da ética onde, seguindo o princípio do dever, a existência se abre, já não ao presente, mas ao projeto; o futuro e a plenitude decorem do mais complexo e menos atingível estádio, o religioso. Neste abre-se a perfetibilidade e a incomensurável necessidade, vendo-se o sujeito como pertença do eterno. Só neste último estádio a sua vida encontrará fundamento.

25. No mesmo sentido, Vergílio, em Invocação ao Meu Corpo, no horizonte de sentido do mundo contemporâneo condicionado pela emergência da técnica sobre o sujeito, conclui que, pela primeira vez na história humana, a questão da existência de Deus perdeu a premência, esgotando-se como obsessão de intelecção. Como tal, considera que, progressivamente, a preocupação para com a existência da divindade tenderá a ser superada pela afirmação das contingências e particularizações da vida hodierna. 
lidade do religioso, o afastamento do divino, como condenação, sine qua non, da experiência humana à finitude e à agonia de uma vida afastada do absoluto e, portanto, da completude e do sentido. Vergílio, ao acentuar a densificação do sujeito, olhado na sua irredutível solidão [sensualista, na potenciação do corpo; moral, na transposição para a sociabilidade], onda ecoa o vazio de Deus, mostra uma profusão do individualismo com a qual os existencialismos nem sempre parecem saber lidar e que ilustra a consequência da afirmação do afastamento divino das equações ontológicas do sujeito. O milagre fantástico da vida é balizado pela disrupção da morte ${ }^{26}$, e o vazio de Deus surge como anulação das âncoras que permitiam o sentido. Centrando o sujeito na sua densificação individualista, às personagens vergilianas falta um sustentáculo que suporte a afirmação do objetivismo individualista que salvaguarda e conserve a afirmação plena da positividade humana. Esta lacuna fundacional é [parcialmente] suprida pela memória, elemento distintivo humano e aproximador à divindade [na medida em que permite a manutenção do ser, isto é, a imortalidade]. Apesar das suas limitações, é a luz que afirma o sujeito na sua afirmação como individuo e possibilita a sua compreensibilidade como ser radicalmente livre ${ }^{27}$.

Esta [tentativa] de requalificação do ser humano, dotado da responsabilidade de se construir na sua plena autonomia, abre o sujeito à tarefa de significação ${ }^{28}$ enquanto ser lançado no jogo da existência,

26. "A importância da morte está na vida (...). A importância da morte está onde a vida é ainda visível". Vergílio Ferreira, Em Nome da Terra, Quetzal, 2009, pp.201 e 202.

27. Sobre a relação entre ética e liberdade, ver Ética e Liberdade - De Vergílio Ferreira a Sartre, de Cassiano Reimão na coletânea de estudos Vergílio Ferreira - da Ficção à Filosofia, organizada por José Antunes de Sousa e Carlos Morujão.

28. Em Vergílio Ferreira, Invocação ao Meu Corpo, Quetzal, 2011, afirma-se um certo teleologismo do universo. A criação do homem não é abordada numa base casuística [que tanto poderia interessar a uma abordagem mais próxima do existencialismo ateu de Sartre], mas como uma fatalidade, uma exigência na autocompreensão. Com Deus ou sem ele - refere Vergílio -, o Universo tem de tomar consciência de si, através do homem, para que realmente exista [ibid, p. 215]. Esta tarefa de significação permite a atenuação do despojamento e do abandono ao absurdo a que o existencialismo de Sartre e Camus parecem destinar o Homem. A mesma leitura pode ser estabelecida a partir da referência ao criacionismo divino: A criação do sujeito decorre da necessidade de reconhecimento de um ser divino. Sem o homem, no fundo, Deus não existe. 
cabendo-Ihe a tarefa de se construir num universo exagerado perante o que pode ser conhecido. É em Estrela Polar que encontramos a explanação mais extrínseca desta reconversão do homem. Seguindo a esteira de Aparição, Estrela Polar procura a afirmação da plenitude criadora do sujeito sem lhe conferir subterfúgios ou interlúdios. Tanto Alberto como Adalberto, personagens, respetivamente, de Aparição e de Estrela Polar, partilham uma mundividência estabelecida nas possibilidades criativas do sujeito, interpretando-se como catalisadores de uma mudança antropocêntrica que, contudo, em ambos os casos, culmina na imposição do real sobre o imaginário. Em ambos os casos, resiste somente a solidão, "necessária, porque é nela que um homem ouve a linguagem de um homem $^{29}$." Estrela Polar estabelece o jogo da finitude e do absurdo existencial com o enquadramento filosófico da trama. O mobile despoletador da memória é, aqui, de forma explícita, a morte: tanto da mulher que se ama [seja ela Alda ou $\mathrm{Aida}^{30}$ ], mas sobretudo do filho na tragédia do inesperado, mostrando como a conotação do homem como um ser de projeto colide com o externalismo de uma realidade que não se deixa encerrar nas pretensões oníricas da vontade. Em Estrela Polar, como no geral da obra de Vergílio, a morte é paradoxalmente inesperada e aguardada. Pressente-se na angústia que acompanha as vivências narrativas; mas chega com o espanto do imponderado. Se em Aparição é Alberto quem recolhe o corpo dilacerado de Cristina ${ }^{31}$, aqui é Adalberto quem atende ao pânico e abraça o corpo pálido e exaurido do filho perdido. É a morte [especificamente esta morte, a perda ontológica pura] que confidencia e confirma a verdade da nossa irredutível solidão: "O universo é grande, um homem chora a uma janela. Está só ${ }^{32 " . ~ R e s t a-l h e ~[s e m p r e] ~ a ~ m e m o ́-~}$ ria para a catarse [que nunca alcança]. O que relembra é a condensação

29. Vergilio Ferreira, Estrela Polar, Portugália Editora, 1962, p.226.

30. Estrela Polar questiona a noção de identidade. Alda e Aida confundem-se no amor de Adalberto, não se sabendo o seu limite ontológico, como se numa vivesse a outra. À morte de Aida, sobra ainda Aida na figura da irmã [adotiva? Gémea?].

31. A morte de Cristina expressa a intransponibilidade do sentido. Representa a arte e como os nossos esforços criativos estão fundamentalmente enraizados [e até dependentes] da morte.

32. Vergílio Ferreira, Estrela Polar, Portugália Editora, 1962, p.300. 
da esperança, a fútil vagueza da vontade que lança no desespero e, simultaneamente, ilude na expectativa de um resgate.

Vergílio mostra desconforto e ambiguidade em relação à questão da morte. Em Estrela Polar é descrita como "estrela de perfeição ${ }^{33 "}$ por abrir ao imutável, à não-adição, expressando a completude do que já não pode ser modificado, a completude do eterno daquilo que fora e ao qual já não se pode acrescentar e que permite a afirmação de que o balanço da humanidade se faça no eterno ${ }^{34}$. É por isso que ela "guarda o reino do sonho para que a vida não o use ${ }^{35 ",}$, isto é, para que a vida o não corrompa. Estabelece-se uma atípica heurística da morte, porquanto se inverte o pólo valorativo: a vida destrói; a morte preserva. Tal decorre da afirmação da existência como projeto, sendo que a efetivação de uma possibilidade comporta a anulação de outras potencialidades. A vida, porquanto efetiva uma possibilidade, pressupõe o termo da amplitude circunstancial que resta no possível.

Esta afirmação mais apolínea da morte, concebida como impulsão para a eternidade a que se acede pela memória, permite a equação do sujeito como entidade individual, mas deixa-lhe a agonia da efemeridade e da frugalidade. Se Deus exist[isse] e nele a minha imortalidade, tudo quanto fiz e acumulei tem um significado. ${ }^{36}$ Mas a afirmação da autonomia do sujeito conduz Vergílio ao afastamento desta visão fiadora de Deus, pelo que a morte não deixa de surgir nas suas obras configurada de uma outra forma: como terror. A morte enquanto limite destrutivo, enquanto dilaceramento das possibilidades ônticas do individuo reconfigura a forma como Deus surge nos romances de Vergílio ${ }^{37}$. Quando não remetido para um esquecimento tímido, oculto no âmago perturbador do

33. Ibid, p.297.

34. Cf. Vergílio Ferreira, Em Nome da Terra, Quetzal, 2009, p.136.

35. Vergílio Ferreira, Estrela Polar, Portugália Editora, 1962, p.297.

36. Vergílio Ferreira, Invocação ao Meu Corpo, Quetzal, 2011 p. 224.

37. Vergílio reconhece, aliás, que a existência de Deus é de algum modo secundária porque responde apenas a um desejo de inteleção. Mas não a questão da sobrevivência do homem. [ibid, p. 240]. 
silêncio, Deus surge como compensador de quem o homem é tributário. A satisfação dos seus desejos torna-se condição para a salvação, motivo pelo qual, temendo-se a morte, se principia também a temer Deus. Perante a certeza da liberdade que resulta de uma vida evidente em si mesma, Deus, seja pela sua ausência, seja pelos constrangimentos que apresenta ao ser-projeto do homem, nunca permite a esquiva ontológica que garanta a esperança.

Projeta-se, então, na obra de Vergílio Ferreira, o homem como referencial axiológico de si mesmo num mundo que assume a distanciação de Deus ${ }^{38}$, num contexto em que é estrela polar e guia de si mesmo. Mas nesta deriva axiológica, apesar do otimismo com que as personagens assumem a missão de evangelizar o novo homem, afirmando-o na sua autonomia e liberdade, a efetivação do projeto revela-se falível. Ao homem apolíneo, dionisíaco, zaratustriano, convicto da sua certeza e arauto da arte, Vergílio contrapõe a tragédia, o remorso e a angústia, legando como pêndulo somente a nossa condenação. A este homem referência de si, acompanha-o as vivências do sentido da recordação. Alberto [Aparição], Adalberto [Estrela Polar], Paulo [Para Sempre] e João [Em Nome da Terra] descobrem-se no âmago da sua solidão analéptica na diáspora por um sentido norteador que permita a tolerância do Tempo. Cada um deles isolado, preso num palco onde a vida é confluência, mas cujo sentido nunca está além do conferido pelo sujeito. Na vida de cada um, diz-nos Vergílio, todos os outros são figurantes e a derradeira história que se conta é sempre um monólogo.

38. Vergílio considera, aliás, que a discussão sobre a existência de Deus perdeu pertinência com a alvorada da técnica. Sendo ainda uma obsessão, pela primeira vez reconhecemos que não o podemos discutir (...), o que é portanto o sinal de que ele tende a morrer como problema. [ibid, p.243]. 


\section{Referências}

ANTUNES DE SOUSA, José e MORUJÃO, Carlos [et al.] - Vergílio Ferreira - da Ficção à Filosofia, Universidade Católica Editora, 2015.

FERREIRA, Vergílio. Aparição, Portugália Editora, 1959.

FERREIRA, Vergílio. Estrela polar, Portugália Editora, 1962.

FERREIRA, Vergílio. Espaço do Invisível I, Arcadia, 1978.

FERREIRA, Vergílio. Espaço do Invisível IV, INCM, 1987.

FERREIRA, Vergílio. Para Sempre, Quetzal, 2008.

FERREIRA, Vergílio. Em Nome da Terra, Quetzal, 2009.

FERREIRA, Vergílio. Invocação ao Meu Corpo, Quetzal, 2011.

GODINHO, Hélder [et al.]. Estudos Sobre Vergílio Ferreira, INCM, 1982. 